\title{
Habilidades socioemocionais e relações étnico-raciais no contexto escolar
}

\section{Edmilson dos Santos Ferreira}

Doutorando do Programa de Pós-Graduação em Educação da Universidade Federal do Rio de Janeiro, PPGE-UFRJ.

\section{José Jairo Vieira}

Professor do Programa de Pós-Graduação em Educação da Universidade Federal do Rio de Janeiro, PPGE-UFRJ.

\section{Andréa Lopes da Costa Vieira}

Professora do Programa de Pós-Graduação em Memória Social da Universidade Federal do Estado do Rio de Janeiro, PPGMS-UNIRIO. 


\section{Resumo}

Este artigo tem por objetivo traçar aproximações entre as habilidades socioemocionais e as relações étnico-raciais no contexto escolar. A metodologia utilizada foi a revisão e analise bibliográfica. No decorrer do artigo, faremos um debate sobre desigualdade social e pobreza, sobre o conceito de habilidades socioemocionais e as relações raciais na educação. Podemos considerar a partir das análises desenvolvidas que as habilidades sociemocionais são fundamentais para a criação de um ambiente social adequado na escola, onde desigualdades, esteróitpos, bullying e discriminações raciais devem ser combatidos e substituídos por ações e políticas que visem a inclusão e sobretudo o convívio sem preconceitos dos diferentes indivíduos que compõe a sociedade.

Palavras-chave: Habilidades socioemocionais. Relações étnico-raciais. Escola. Corporeidade.

\section{Abstract}

This article aims to draw approximations between socio-emotional skills and ethnicracial relations in the school context. The methodology used was the bibliographic review and analysis. In the course of the article, we will discuss social inequality and poverty, the concept of social-emotional skills and race relations in education. We can consider from the analyzes developed that the social skills are fundamental for the creation of an adequate social environment in the school, where inequalities, stereotypes, bullying and racial discrimination must be fought and replaced by actions and policies aimed at the inclusion and, above all, without prejudices of the different individuals that make up the society.

Keywords: Social-emotional skills. Ethnic-racial relations. School. Corporeality. 


\section{Introdução}

Este trabalho pretende tecer as primeiras aproximações sobre o desenvolvimento das habilidades socioemocionais e como estas permitem a construção de caminhos para a reflexão acerca das relações étnico-raciais no contexto escolar. Elegemos a escola como local privilegiado de encontros, troca de experiências e saberes onde as desigualdades raciais se manifestam e os movimentos de resistência nos levam a desenvolver habilidades sociais com uma carga emocional que precisa ser investida por uma relação direta com o conhecimento visando a construção de um ambiente democrático.

Organizamos este estudo em três sessões: na primeira sessão, discutirmos desigualdade e pobreza a partir dos estudos de Kerstenetzky (2000), tecemos uma aproximação com os estudos de Lebreton (2009) para compreendemos como a relação com o corpo infantil afeta as interações das crianças. Apresentamos argumentos para construção do conceito de habilidades socioemocionais para tanto, selecionamos alguns elementos das ciências sociais, tomando por base os estudos de Stehr (2000) e resgatamos algumas lições de Sen para $\mathrm{Na}$ segunda sessão, procuramos refletir sobre alguns princípios teórico-metodológicos, fizemos uma revisão da literatura inicial sobre as relações raciais, os efeitos do preconceito e os reflexos na escola. E na última sessão tecemos breves considerações finais.

\section{Desigualdade e as suas relações socioemocionais}

Célia Kerstenetzky faz uma análise acerca das Lições de Sen para discutir desigualdade e pobreza, destacamos a Economia enquanto o saber voltado à produção de riqueza material, mas no sentido de preocupar-se para o bem-estar pessoal sem perder de vista a dimensão ética que poderia favorecer os comportamentos cooperativos, dessas relações pode emergir o reconhecimento do fazer coletivo, que ao mesmo tempo se expresse em um comportamento reciproco. Ou seja,

Se a reprocidade não é considerada importante intrinsecamente e sim instrumentalmente, e esse reconhecimento se expressa de fato em 
comportamento reciproco para melhor atingir os objetivos de cada pessoa, é difícil argumentar que o 'objetivo real' da pessoa é seguir a reciprocidade em vez de seus respectivos objetivos reais (Sen, 1999, p. 102).

$\mathrm{O}$ argumento da reciprocidade nos leva a pensar que a economia do bem-estar sugere a relevância do comportamento autointeressado e que não esteja baseado em regras convencionais, nem tão pouco no individualismo. Sen considera a motivação uma característica intrínseca e pode ser incorporada ao autointeresse, gerando um conjunto de valores por parte dos indivíduos.

Sen também critica o utilitarismo, no sentido de apoiar-se na utilidade e nas preferências do indivíduo. Ou seja, "o utilitarismo distorceria a avaliação dos estados sociais possíveis sobretudo ao sancionar, de um lado, o conformismo daqueles que sofrem opressão e discriminação sociais continuadas" (Kerstenetzky, 2000, 116).

Os estudos de Le Breton nos apoiarão para compreender como a relação com o corpo afeta o desenvolvimento das crianças e suas interações com o grupo. Para Le Breton (2009) a aparência apresenta e representa o sujeito, envolve o comportamento, os modos de vestir e cuidar do corpo, aspectos que revelam uma linguagem corporal simbólica que diz respeito ao pertencimento social e cultural. E se constitui também de aspectos físicos como altura, massa e características estéticas. O cotidiano das crianças é marcado pelo desenvolvimento de sentimentos como alegria, tristeza e angustia onde a subjetividade dos diferentes contextos enquanto lugar das emoções. O sentimento de inferioridade pode ser observado em situações que envolvem o cabelo liso, a pele clara como referencial hegemônico reproduzido pelos filmes infantis comerciais que pode conduzir a reforço de situações de negação racial.

David Lebreton valoriza as relações estabelecidas com o outro. E este representa a construção social do corpo, para o autor, é na relação com o outro que exploramos as percepções sensoriais e a linguagem. Nesse contexto, as crianças por vezes, estabelecem uma hierarquia entre pobres e ricos e usam como referência a cor da pele e se os cabelos são lisos ou cacheados.

Há uma cumplicidade das famílias sobre as atitudes racistas que podem reforçar o sentimento de inferioridade entre as crianças negras e pardas. As crianças não percebem ou não distinguem o porquê de serem preteridas nas brincadeiras e na organização das atividades de livre escolha, seu comportamento traduz em lágrimas ou 
em silêncio. Outrora, a reação pode ser interpretada como agressividade. Esses sentimentos expressam "uma combinação de sensações corporais, de gestos e de significados culturais apreendidos por intermédio das relações sociais” (Le Breton, 2009, p.113).

Nesse sentido, as relações socioemocionais vêm ganhando destaque no cenário acadêmico por facilitar as interações com os demais sujeitos do grupo. Para introduzir o tema recorremos aos estudos Stehr (2000) que busca no campo das ciências sociais elementos para compreender as desigualdades sociais presentes na sociedade. Seus estudos partem da premissa básica das teorias da desigualdade nas sociedades industriais, assim, as hierarquias sociais estão diretamente relacionadas com os processos produtivos e sua organização. E consequentemente, afeta a relação do sujeito com o trabalho, o aluguel, os juros e o lucro, por exemplo.

A sociedade do trabalho ou o capitalismo forjou a nova classe média ampliando o seu potencial de consumo. "Apesar disso, o status social dos que não estão ativos continua a ser visto, por uma perspectiva adscrita e em contradição com a tendência para a individualização na sociedade moderna, como dependente do processo produtivo" (Stehn, 2000, p. 103). Ao mesmo tempo em que o processo de modernização geraria um sistema de desigualdade mais equilibrado com o surgimento de aptidões e habilidades que favoreceria a mobilidade individual.

O autor faz referência ao conhecimento, entendido como capacidade para entrar em ação e se insere, nesse contexto, como processo capaz de desenvolver as desigualdades sociais. Além da dimensão dada à ascensão do "conhecimento", como principio da estratificação, enquanto possibilidade de acesso a uma posição mais elevada no corpo social da instituição.

Por exemplo, a capacidade de ler e escrever na língua dominante tem um papel tão importante nos sistemas de desigualdades quanto outras habilidades culturais, dependendo da diversidade de uma cultura, tanto quanto o saber religioso pode influir na posição social do sujeito, como recurso para manter a estrutura de desigualdade em relação aos atributos individuais onde prevalece à capacidade de autoafirmação para atingir os diferentes contextos sociais almejados.

Nico Stehn (2000) nos provoca ao afirmar que o conhecimento deveria ser chamado de pacote de competências sociais: 


\begin{abstract}
um pacote amplo e heterogêneo de competências, o conhecimento tem efeitos específicos sobre o processo de formação da desigualdade, ao passo que os resultados continuam a envolver hierarquias distribuídas em dimensões tradicionais, ou não tão tradicionais assim (p. 117).
\end{abstract}

Nesse sentido, o autor relaciona as mais importantes competências sociais que nos apoiaremos para construirmos o conceito de habilidades socioemocionais:

A capacidade de tirar partido do discernimento. Refere-se à habilidade de extrair vantagens das situações, seja no campo dos negócios, jogos ou situações diversas; Mas sempre atentos às regras e valores que regem a conduta social;

A facilidade para organizar recursos de proteção. Trata-se da habilidade de mobilizar conhecimentos para assegurar os direitos legais e o patrimônio material ou simbólico com potencial de evitar danos a um indivíduo ou a instituição;

$A$ autoridade para falar. Esta habilidade é um diferencial que se baseia cada vez mais em diferentes conhecimentos, e por vezes, associada a experiência escolar, consiste em se posicionar com clareza seja diante de seus pares, líderes ou para uma plateia leiga. Bourdieu (1975) destaca que em uma sociedade de classes, as diferenças culturais, especialmente, as classes burguesas dominam o seu patrimônio cultural que se constitui de valores e formas de conduta e o domínio da oratória. Mas reconhece também que as classes trabalhadoras possuem outras características culturais que podem the conferir status equivalentes. E conduz o sujeito a se autoafirmar no grupo.

A capacidade de preparar-se para desafios. Esta representa bem a estratificação social baseada no conhecimento. Consiste na habilidade de contestação das práticas da chefia ao ampliar a autonomia do sujeito, enquanto se posiciona diante das situações adversas, por vezes, autorregulada e adota estratégias diferenciadas.

A capacidade de evitação e exclusão. Consistem na habilidade de evitar os riscos, mediar os conflitos ou assumir as consequências pela participação ou não, em transações materiais ou simbólicas. Assim como se posicionar diante de situações de vulnerabilidade social.

Anita Abed (2014) em sua pesquisa de doutorado, afirma que as habilidades socioemocionais podem:

promover o fortalecimento das inteligências interpessoal e intrapessoal, o que é fundamental para qualquer ser humano viver em sociedade e estabelecer vínculos saudáveis consigo próprio e com os outros, mas especialmente importante para atender as pessoas que têm essas inteligências como seus pontos fortes (ABED, 2014, p. 75). 
Portanto, as habilidades socioemocionais consistem em um conjunto de saberes/conhecimentos mobilizados diante de diferentes situações que demandam por equilíbrio social e emocional para tomada de decisões seja de ordem prática, no que diz respeito às situações do cotidiano, nas interações sociais, nas relações de trabalho, seja âmbito acadêmico. As relações socioemocionais podem ser desenvolvidas ao longo da vida e se expressam como potência de acordo com as características e experiências individuais que favorecem o coletivo.

O desenvolvimento das relações socioemocionais se expressam em diferentes contextos, destacamos a seguir as relações étnico-raciais como pressuposto de situações que demandam enfrentamento e posicionamento político e militância.

\section{Relações raciais e os efeitos do preconceito}

Os estudos de Florestan Fernandes e Roger Bastide (1955), descreveram a diversidade de atitudes na relações raciais e afirmam que, dadas as condições sociais de exploração econômica, estas favorecem a formação de símbolos sociais e de padrões em torno da raça ou cor da pele. "Ou seja, o preconceito existe, mas não é suficiente para explicar a desigual inserção dos negros na estrutura social” (LIMA \& PRATES, 205, p. $165)$.

$\mathrm{Na}$ década de 1970, a expressão "preconceito de cor” deu lugar ao termo "discriminação" e a sentença "desigualdades raciais" passaram a ser mais recorrentes. O trabalho de Carlos Hasenbalg (1979) investigou as relações raciais contemporâneas e postulou sobre a incompatibilidade entre a industrialização e o racismo. Segundo ele, a industrialização ainda não eliminou a questão racial como critério que estrutura as relações sociais.

Nos anos 1980 e 1990, os estudos de Elza Berquó (1988) analisou a expectativa de vida das crianças e a mortalidade infantil dos segmentos mais pobres da população, composto predominantemente por negros e pardos. Já as pesquisas de Barcelos (1992) e Hasenbalg \& Silva (1988) destacaram as desigualdades entre crianças negras e brancas mesmo diante de características similares de classe, como origem social e renda familiar per capita. 
A relação entre a origem familiar e a desigualdade racial nos faz pensar que brancos oriundos de familiar mais bem posicionadas na hierarquia social facilitaria a produção de status. A esse respeito, Nelson Silva (1988) analisou a mobilidade social intergeracional e a aquisição de renda entre brancos e negros, e observou que os trabalhadores com a mesma posição na hierarquia ocupacional têm retornos monetários diferentes. Dessa forma, a mobilidade social entre os negros e pardos tem apresentado chances menores de ascensão social.

Outro tema que se articula a esta análise está relacionado com a recente inquietação dos pobres urbanos da Europa, da América do Norte e mais recentemente, no Brasil. Wacquant considerou uma resposta (socio)lógica à violência estrutural desencadeada por uma série de transformações econômicas e sociopolíticas.

\footnotetext{
Tais mudanças resultaram em uma polarização de classes que, combinada com a segregação racial e étnica, está produzindo uma dualização da metrópole, que ameaça não apenas marginalizar os pobres como condená-los à redundância social e econômica direta (Wacquant, 2001, p. 29).
}

Essa violência apresenta basicamente dois elementos: o desemprego em massa para segmentos inteiros da classe trabalhadora e; o exílio em bairros e comunidades decadentes onde a presença do poder público acentua a violência e a moradia nesses lugares aumentam com a imigração. Os "novos imigrantes” ocupam as comunidades mais pobres dos centros urbanos, onde podem se estabelecer com a assistência fundamental para adaptação em um novo país.

$\mathrm{O}$ autor traz uma análise consistente para a compreensão dos mecanismos da nova pobreza, provocada pelo desemprego e o movimento migratório nas sociedades avançadas e propõe uma reformulação do Estado de Bem-estar, considerando as políticas sociais que envolvam não apenas a geração de emprego, mas o direito a subsistência para além dos programas de complementação de renda. 


\section{Reflexo na escola: oportunidade de acesso às crianças e jovens negros}

As ações afirmativas tiveram como seu primeiro registro no Programa Nacional de Direitos Humanos de 1996 e reconhecia as demandas sociais ao considerar as "ações afirmativas para o acesso de negros aos cursos profissionalizantes, à universidade e às áreas de tecnologia de ponta”, como resultado da Conferência Mundial sobre Educação para Todos (1990). Embora pouco tenhamos avançados em direção a promoção de igualdade social, o a conferência manifestou a preocupação das organizações internacionais em universalizar o a educação em busca equidade social.

Os movimentos sociais participaram ativamente desse processo que vinculou raça ao ensino superior. Movimentos como o Educação e Cidadania de Afrodescendentes e Carentes (Educafro) e o Pré-vestibular para negros e Carentes (PVNC) se organizaram e assumiram coletivamente a iniciativa de ação afirmativa oferecendo cursos preparatórios para que jovens e adultos tivessem acesso os conceitos previstos nos exames de ingresso às universidades. As aulas são ministradas por professores voluntários e alunos de licenciatura com sentimento de pertença ao movimento.

O debate sobre as ações afirmativas ganhou centralidade no movimento negro nas últimas décadas de combate às desigualdades sociais, visto que:

\footnotetext{
fizeram emergir politicamente o reconhecimento da desigualdade racial; trouxeram para o centro da política o debate sobre a ação afirmativa; estabeleceram uma das formas mais eficazes de pressão contra o Estado; e problematizaram o acesso diferenciado ao ensino superior (VIEIRA, 2014, p. 137).

Entender esta "descoberta" e encontrar a gênese da adoção de estratégias de ação afirmativa e/ou antidiscriminátórias pressupõe delimitar como marcos dois eventos que, apesar de distintos em sua natureza, tornaram-se emblemáticos para difusão da ideia de discriminação positiva: a implementação de cursos comunitários denominados Pré-Vestibulares para Negros e Carentes - PVNC; e, a elaboração do Programa Nacional de Direitos Humanos (1996)" (VIEIRA \& VIEIRA, 2013, p. 141).
}

A análise dos autores (VIEIRA, 2014; VIEIRA \& VIEIRA, 2013) indicam que pobres e negros promoveram a igualdade social ou uma discriminação positiva rompendo o acesso ao nível superior ao mesmo tempo que o processo educacional se 
FERREIRA, E. de S. et al. Habilidades socioemocionais e relações étnico-raciais no contexto escolar. R. Cientîfica UBM - Barra Mansa (RJ), ano XXII, v. 19, n. 37, 2. Sem. 2017. p. 157-169.

configura como mecanismo para se conquistar um status social que envolve democracia, mérito e privilégio; acentuando o debate sobre a promoção da desigualdade social.

Nos gráficos a seguir, podemos observar que atingimos a universalização do acesso das crianças negras ao ensino fundamental (Gráfico 1), o que favorece o compromisso com estudos voltados às crianças e seus saberes, considerando o quanto elas podem contribuir para que os professores possam aprender a negociar os seus desejos com elas e para elas.

Em seus gráficos, Lima e Prates (2015) reconhecem que é inegável a redução da desigualdade racial entre os alunos do ensino médio, embora o distanciamento entre brancos em relação a pretos e pardos permaneçam (Gráfico 2), vale destacar que a universalização do acesso ao ensino médio ampliou a demanda pelo acesso ao ensino superior.

\section{Reflexo na escola}

Mudanças nas taxas de escolarização líquida* nos diferentes níveis de ensino

\begin{tabular}{|c|c|c|c|}
\hline \multicolumn{4}{|c|}{ Gráfico 1} \\
\hline Eranco & - Preto & ॥ Pardo & - Total \\
\hline
\end{tabular}

\section{ENSINO FUNDAMENTAL [7 a 14 anos]}

Única faixa etária cuja frequência à escola é praticamente universal (98\%) em 2010

$$
\%
$$

100

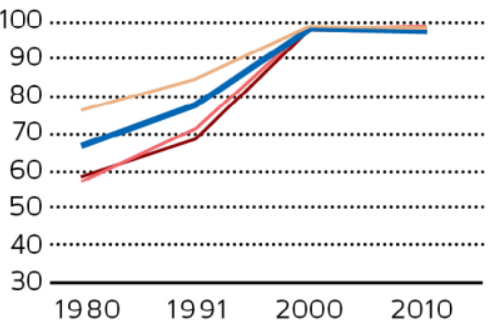

Gráfico 2

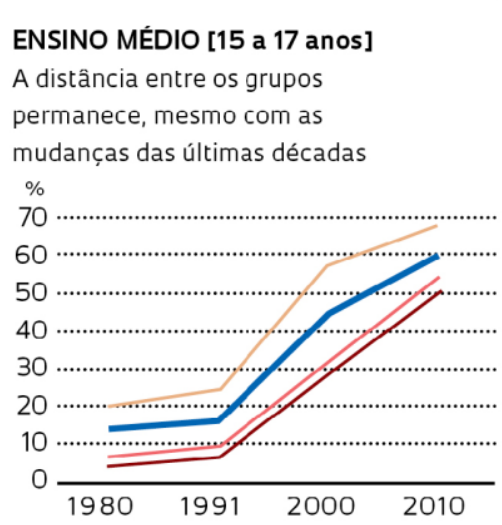

Gráfico 3

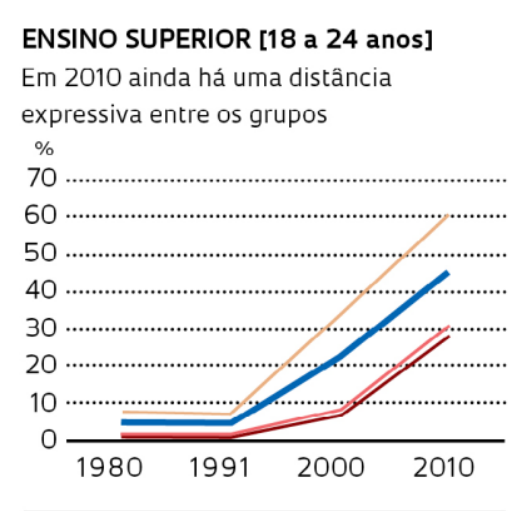

* Escolarização líquida é a participação dos estudantes nos níveis de ensino considerados adequados ao seu grupo etário: alunos de 7 a 14 anos no ensino fundamental, de 15 a 17 anos no ensino médio e de 18 a 24 anos no nível superior.

Fonte: IBGE, Censos Demográficos 1980-2010. Tabulações Especiais do Centro de Estudos da Metrópole (CEM)

Já o Gráfico 3, denuncia que as desigualdades raciais são mais acentuadas no ensino superior. Para Lima e Prates (2015), "as taxas dos pretos e pardos eram praticamente insignificante" (p.175). Considerando que, a expansão do ensino superior nas universidades públicas não recebeu o investimentos suficiente para democratizar o acesso à universidade. Enquanto, a ampliação de vagas nas universidades privadas 
recebeu mais investimento público por conta do Programa Universidade para todos (ProUni). Contudo,

O ProUni é curiosamente direcionado às instituições privadas e traz, como público-alvo preferencial a população classificada como carente. Utiliza de um corte racial, sem que exerça, no entanto, determinação sobre as possibilidades de acesso (VIEIRA \& VIEIRA, 2013, p. 150).

Logo, as políticas públicas de inclusão ao ampliarem o número de vagas nas universidades privadas, reproduziram a desigualdade e elitização presente na sociedade. E embora as ações afirmativas seja uma conquista significativa para o movimento negro, as políticas públicas se revelaram generalistas pela pequena reserva de vagas destinadas a população negra entre outras minorias, além de incluir os candidatos às licenciaturas e o corte por renda per capta.

\section{Considerações finais}

O presente estudo procurou descrever características que sustentam as aproximações entre as habilidades socioemocionais e as relações étnico-raciais. Apresentamos enfoques que nos levaram ao debate sobre pobreza, desigualdade racial e luta de classe. Em geral, valorizamos a cooperação, o espirito de liderança, o autocontrole, o trabalho em equipe, a criatividade, o otimismo e a motivação para o enfrentamento das questões que afetam a qualidade de vida, as relações de trabalho e que prejudicam as relações sociais.

Nessa direção, os movimentos sociais ao constituírem os coletivos populares não podem se dar por satisfeitos com políticas compensatórias que acentuam as desigualdades sociais e raciais. Os coletivos, o movimento negro, em especial, estão em busca de políticas de reconhecimento e de direito à pertença, mas precisamos incluir nesse debate o diálogo com os sujeitos que compreendem, defendem as ações afirmativas e também reivindicam o direito ao pertencimento as suas políticas e instituições, enquanto sujeitos de direitos. Dessa forma, branco, negros, pardos e outras etnias possam estar lado a lado em defesa de uma sociedade mais justa e com menos desigualdades. 


\section{Referências}

ABED, Anita L.Z. O desenvolvimento das habilidades socioemocionais como caminho para a aprendizagem e o sucesso escolar de alunos da educação básica. São Paulo. Tese de Doutorado, 2014.

BARCELOS, Luiz C. Raça e realização educacional no Brasil. Rio de Janeiro. Dissertação de Mestrado, Sociologia, IUPERJ, 1992.

BERQUÓ, Elza. "Demografia da desigualdade: algumas considerações sobre os negros no Brasil”. In: Anais... VI Encontro Nacional de Estudos Populacionais, 1988, vol.3, p.89-110.

BOURDIEU, Pierre. The specificity of the scientific field and the social conditions of the progress of reason. Social Science Information, 14: 19-47, 1975.

CONFERÊNCIA Mundial de Educação para Todos. Declaração Mundial de Educação para Todos. Plano de Ação para Satisfazer as Necessidades Básicas de Aprendizagem. Brasília, DF: UNIFEC, 1990.

FERNANDES, Florestan. A luta contra o preconceito de cor. ln: BASTIDE, Roger \& FERNANDES, Florestan. Relações raciais entre negros e brancos em São Paulo. São Paulo: Anhembi, 1955.

HASENBALG, Carlos \& N. V. SILVA, N. S.(org.). Estrutura Social, Mobilidade e Raça. Rio de Janeiro, Vértice, 1988.

LE BRETON, David. As Paixões Ordinárias: Antropologia das Emoções. Petrópolis, Vozes, 2009.

LIMA, Márcia \& PRATES, Ian. Desigualdades raciais no Brasil: um desafio persistente. In: ARRETCHE, Marta (org.). Trajetória das desigualdades: como o Brasil mudou nos últimos 50 anos. São Paulo: Editora UNESP, 2015.

SILVA, Nelson do V. Cor e Processo de Realização Socioeconômica. In HASENBALG, Carlos \& N. V. SILVA, N. S.(org.) Estrutura Social, Mobilidade e Raça. Rio de Janeiro, Vértice, 1988. 
KERSTENETZKY, Celia Lassa. Desigualdade e pobreza: Lições de Sen. Revista Brasileira de Ciências Sociais. Vol. 15, n. 42, fevereiro/2000.

SEN, A. Sobre ética e economia. São Paulo, Companhia das Letras, 1999.

STEHN, Nico. Desigualdade de classe à desigualdade de conhecimento. Revista Brasileira de Ciências Sociais. Vol. 15, n. 42, fevereiro/2000.

WACQUANT, Loic. Os condenados da cidade: estudo da marginalidade avançada. Rio de Janeiro: Revan: Fase, 2001.

VIEIRA, ANDRÉA L.C. De qual inclusão se fala, quando o assunto é ensino superior? Uma análise comparativa entre as propostas de cotas raciais e o Programa Universidade para Todos (ProUni). In: FARIA, Patrícia S. \& PINHEIRO, Márcia L. [org.]. Novos estudos em relações étnico-raciais Sociedades e politicas públicas. Rio de Janeiro: Editora Contra Capa, 2014.

VIEIRA, ANDRÉA L. C. \& VIEIRA, J. Jairo. Políticas Educacionais de ação afirmativa no Brasil. Por quais caminhos? In: JEFFREY Débora C. \& AGUILAR Luis Henrique (org). Balanço da politica educacional brasileira (1999-2009): açôes e programas. Campinas, São Paulo: Mercado das Letras, 2013. 